\title{
Targeted immunotherapy of high-grade cervical intra-epithelial neoplasia: Expectations from clinical trials (Review)
}

\author{
JEAN-LUC BRUN ${ }^{1,2}$, JOSÉ RAJAONARISON ${ }^{1}$, NICOLAS NOCART ${ }^{1}$, \\ LAURA HOARAU $^{1}$, STÉPHANIE BRUN $^{1}$ and ISABELLE GARRIGUE ${ }^{2,3}$ \\ ${ }^{1}$ Department of Obstetrics and Gynecology, Hospital Pellegrin, University of Bordeaux, \\ ${ }^{2}$ UMR 5234, Microbiology and Pathogenicity, University of Bordeaux; ${ }^{3}$ Laboratory \\ of Virology, Hospital Pellegrin, University of Bordeaux, 33076 Bordeaux, France
}

Received September 7, 2017; Accepted November 13, 2017

DOI: $10.3892 / \mathrm{mco} .2017 .1531$

\begin{abstract}
Targeted immunotherapy of high-grade cervical intra-epithelial neoplasia (CIN) has been developed as an alternative to conization, to preserve future reproductive outcomes and avoid human papillomavirus (HPV) persistence. The objectives of the review are to present drugs according to their process of development and to examine their potential future use. A search for key words associated with CIN and targeted immunotherapy was carried out in the Cochrane library, Pubmed, Embase, and ClinicalTrials.gov from 1990 to 2016. Publications (randomized, prospective and retrospective studies) in any language were eligible for inclusion, as well as ongoing trials registered on the ClinicalTrials.gov website. Targeted immunotherapy includes peptide/protein-based vaccines, nucleic acid-based vaccines (DNA), and live vector-based vaccines (bacterial or viral). A total of 18 vaccines were identified for treatment of CIN at various stages of development, and the majority were well-tolerated. Adverse effects were primarily injection site reactions and flu-like symptoms under grade 2 . The efficacy of vaccines defined by regression of CIN2/3 to no CIN or CIN1 ranged from 17 to $59 \%$ following a minimum of a 12 -week follow-up. In the majority of studies, there was no association demonstrated between histological response and HPV clearance, or between histological or virological response and immune $\mathrm{T}$ cell response. Given that the spontaneous regression of CIN2/3 is $20-25 \%$ at 6 months, targeted immunotherapy occurs an additional value, which never reaches $50 \%$, with one trial an exception to this. However, research and development on HPV eradication drugs needs to be encouraged, due to HPV-associated disease burden.
\end{abstract}

Correspondence to: Professor Jean-Luc Brun, Department of Obstetrics and Gynecology, Hospital Pellegrin, University of Bordeaux, Place Amélie Raba Léon, 33076 Bordeaux, France

E-mail: jean-luc.brun@chu-bordeaux.fr

Key words: targeted immunotherapy, high-grade cervical intra-epithelial neoplasia, human papillomavirus

\section{Content}

1. Introduction

2. HPV Biology

3. Concept and types of targeted immunotherapy

4. Peptide/protein-based vaccines

5. DNA-based vaccines

6. Live-vector-based vaccines

7. Conclusion

\section{Introduction}

High-grade cervical intra-epithelial neoplasia (CIN 2/3) is known to be attributable to persistent infection with high-risk human papillomavirus (HR-HPV). The standard treatment consists in ablation or excision, HPV infection leads to raised frequency of conization once CIN 2/3 have been identified. However, obstetrical complications and recurrence may occur after conization: The relative risk of premature delivery, premature rupture of membranes, and intra-uterine growth retardation ranged from to 1.5 to 2.7 after cold knife and loop excision $(1,2)$. In a population-based cohort study in Norway which mixed data on conization and pregnancy outcomes, the rate of premature delivery increased from $7 \%$ in women giving birth before conization to $17 \%$ in women giving birth after conization (3). The relative risks of late abortion $<24$ weeks and premature delivery between 24 and 27 weeks were 4.0 and 4.4 , respectively (3).

Conization treats the lesion, but does not systematically treat the infection and patients may relapse. In a study of 610 women followed up after conization, $37 \%$ were still positive for HR-HPV at 5 months. The average cumulative rate of recurrent high-grade lesions was $7 \%$. The risk of recurrence was higher for HPV16 (37\%) than for other HR-HPV (11\%) and for low-risk (LR)-HPV (1.5\%) (4).

Prophylactic vaccines do not cover the population globally and have no therapeutic effect. In a randomized trial including HR-HPV positive women at entry, vaccinated either with a bivalent vaccine Cervarix ${ }^{\circledR}$ or control, the viral clearance did not significantly differ at 12 months (49 vs. 50\%) between the two groups (5). Quadrivalent vaccine Gardasil ${ }^{\circledR}$ was also not effective to prevent CIN2/3 in women HPV positive by PCR (6). 
Non-surgical treatment may be a useful option for women to preserve future reproductive outcome and avoid HPV persistence.

Targeted immunotherapy is one of these options. Research into and development of targeted immunotherapy is active, challenging and ongoing. A number of reviews have been published on this topic recently (7-9). Main study reports were missing in one review, whereas others mixed phase 1 and 2 studies, including both invasive cervical cancer and CIN2/3. The objectives of this review are to present the products according to their development process, to describe phase $2 / 3$ study results exclusively on high-grade CIN and to question the future of targeted immunotherapy.

\section{HPV biology}

HPVs are non-enveloped, double-stranded, circular deoxyribonucleic acid (DNA) viruses belonging to the Papovaviridae family. Their genome encodes six 'early' proteins (E1, E2, E4, E5, E6 and E7) and two 'late' proteins (L1 and L2). The former proteins co-operate with cellular gene products to enable viral DNA replication, whereas the latter proteins make up the structural components of the viral capsid associated with the packaging of new virions. HPV DNA normally replicates in episomal form. It may be incorporated into host DNA, and this frequently leads to the deletion of a number of viral genes, including several early (E2, E4 and E5) and late (L1 and L2) genes. E6 and E7 are thus the main proteins expressed in the infected cells. Since E2 is a transcriptional repressor of E6 and E7, loss of E2 brings about upregulation of the E6 and E7 genes. The E6 and E7 proteins interact with vital cell cycle regulatory proteins, the p53 and retinoblastoma proteins respectively. The uncontrolled expression of E6 and E7 proteins brings about the disruption of cell cycle regulation and genomic instability, and thus participates in the progression of HPV related oncogenesis (10).

\section{Concept and types of targeted immunotherapy}

Two different stages of the oncogenic infection process are targeted by vaccine-mediated immune strategies: Initial and established infection. To prevent initial infection, the prophylactic vaccines induce neutralizing antibody responses against L1 late protein inhibiting HPV from binding and entering the cell. Since these vaccines are currently used in clinical practice, they will not be examined in this review $(5,6)$. Targeted immunotherapy aims to eliminate or diminish infected cells by priming cytotoxic $\mathrm{T}$ cells against infected cells and upregulating major histocompatibility (MHC) Class I expression. The design of these vaccines is predicated on the presence of episomal replicating virus or integrated viral sequences. Immunotherapy mainly targets E6 and E7 proteins since infected basal epithelial cells and cervical cancer cells do not strongly express L1 and/or L2 capsid antigens (11). Furthermore, as HPV-16 along with CIN2/3 is responsible for around half of all invasive cancer globally most clinical studies have concentrated on E6 and E7 proteins of this genotype $(12,13)$. The types of targeted immunotherapy of CIN2/3, according to the various formulations reported in the literature and/or registered on the ClinicalTrials.gov website are shown in Table I. Technologies to create therapeutic HPV vaccines include peptide/protein-based vaccines, nucleic acid-based vaccines (DNA only, as ribonucleic acid (RNA)-based vaccines are not available for CIN), live vector-based vaccines (bacterial or viral), and whole cell vaccines derived from dendritic cells or even tumor cells (although not available for CIN) $(7-9,14,15)$.

\section{Peptide/protein-based vaccines}

Peptide-based vaccines. Peptides derived from HPV antigens may be administered directly to vaccinate against HPV. Dendritic cells take up HPV antigenic proteins which are presented to human leukocyte antigen (HLA) molecules along with the MHC class I and/or class II pathways to stimulate an immune response against the pathogen. The polymorphic character of HLA molecules necessitates the identification of specific immunogenic epitopes of HPV antigens before developing the vaccine. Adjuvants such as chemokines, cytokines and costimulatory molecules must be used to improve vaccine potency (16).

Phase I/II human clinical trials, have shown that peptide vaccines are safe and well-tolerated in patients with advanced cervical cancer. Detection of $\mathrm{T}$ helper responses and inconstantly HPV-specific cytotoxic T lymphocyte responses, and cytokine production have been observed (14,17-19). However, no response in terms of tumor control was reported.

In a phase I study, 18 women with CIN2/3 related to HPV16 were vaccinated with HPV-16 E7 peptides developed using amino acids 12-20 +/-86-93 encoded by the E7 gene by Peninsula Labs, Inc (Belmont, CA). Subcutaneous administration of the vaccine took place 4 times at 3 -week intervals at escalating doses (100 to 2,000 $\mu \mathrm{g}$ per dose). Conization was performed at 12 weeks. Complete clinical and histological regression (no CIN) was observed in 3 patients (17\%) whereas the response was partial in 6 patients $(33 \%)$. HPV-16 DNA cleared on smears in 12 patients $(67 \%)$. However, a HPV-16 RNA signal remained positive in all tissue specimens. An E7-specific cytokine release was observed in 10 patients (62\%), but immune response was not correlated with regression of the lesion (20).

The peptide-based vaccine developed by the Leiden University Medical Center in the Netherlands has been studied the most since good efficacy and tolerance have been reported in patients with vulvar intra-epithelial neoplasia (21). This vaccine contains 9 HPV-16 E6 and 4 HPV-16 E7 synthetic peptides of 25-35 amino acids along with an overlap of 10-14 amino acids, in an emulsion with incomplete Freund's adjuvant (Montanide ISA-51, Seppic). In a randomized trial including 9 patients with high grade CIN and HPV-16, the vaccine was administered twice subcutaneously at 3 -week intervals $(300 \mu \mathrm{g}$ per peptide) (22). A conization was performed at 7 weeks. The main side effects observed were flu-like symptoms and reactions at injection sites. In all patients, a marked HPV-specific IFNy-associated T-cell response was observed using ELISPOT. However, no HPV clearance was detected at the time of conization and it was too early to assess the histological impact of the vaccine. Inclusion rates were affected by motivational problems leading to the postponement of treatment of CIN2/3 and caused the study to be abandoned prematurely. For this 
Table I. Description of targeted immunotherapy formulations.

\begin{tabular}{|c|c|c|}
\hline Formulations & Main characteristics & Description \\
\hline Peptide-based vaccines & $\begin{array}{l}\text { Safe } \\
\text { Stable } \\
\text { Easy to produce } \\
\text { MHC specific } \\
\text { Poor immunogenicity } \\
\text { Adjuvants required }\end{array}$ & $\begin{array}{l}\text { HPV-16 E7 peptides (Peninsula Labs Inc, CA, USA) (20) } \\
\text { HPV-16 E6/E7 peptides and incomplete Freund's adjuvant (Leiden } \\
\text { University Medical Center, The Netherlands) (21) }\end{array}$ \\
\hline Protein-based vaccines & $\begin{array}{l}\text { Safe } \\
\text { Stable } \\
\text { Easy to produce } \\
\text { Not MHC specific } \\
\text { Low immunogenicity } \\
\text { Adjuvants required }\end{array}$ & $\begin{array}{l}\text { PD-E7 fusion protein: HPV-16 E7 and AS02B adjuvant (GSK } \\
\text { Biologicals, Belgium) }(26,27) \\
\text { HPV-16 E6/E7 fusion protein and ISCOMATRIX adjuvant (Iscotec } \\
\text { AB, Sweden) (28) } \\
\text { SGN-000101: HPV-16 E7 and heat shock protein (Nventa, CA, } \\
\text { USA) (29-31) } \\
\text { TVGV-1: PEK fusion protein and GPI-0100 adjuvant (TheVax } \\
\text { Genetics Vaccine Co., FL, USA) }\end{array}$ \\
\hline DNA-based vaccines & $\begin{array}{l}\text { Safe } \\
\text { Stable } \\
\text { Easy to produce } \\
\text { Low immunogenicity } \\
\text { No neutralizing antibody } \\
\text { protection } \\
\text { Repeat administration possible }\end{array}$ & $\begin{array}{l}\text { ZYC101a: HPV-16 and HPV-18 E6/E7 (MGI Pharma, MN, } \\
\text { USA) }(32,33) \\
\text { VGX-3100: HPV-16 and HPV-18 E6/E7 (Inovio Pharmaceuticals, } \\
\text { PA, USA) }(34,35) \\
\text { pNGVL4a-CRT/E7 (Detox): HPV-16 E7 (NCI RAID program, } \\
\text { USA) (36) } \\
\text { pNGVL4a-Sig/E7(Detox)/Hsp70: HPV-16 E7 (NCI, USA) (37) } \\
\text { GX-188E: HPV-16 and HPV-18 E6/E7 (Genexine Inc., Korea) } \\
\text { VB10: HPV-16 E6/E7 (Vaccibody AS, Norway) }\end{array}$ \\
\hline Natural viral vectors & $\begin{array}{l}\text { Strong immunogenicity } \\
\text { Neutralizing antibodies } \\
\text { Repeat administration potency } \\
\text { reduction }\end{array}$ & $\begin{array}{l}\text { TA-HPV: Recombinant vaccinia vector encoding HPV-16 and HPV- } \\
\text { 18 E6/E7 (Xenova group PLC, United Kingdom) }(40,41) \\
\text { MVA-E2: Modified vaccine of Ankara encoding bovine } \\
\text { papillomavirus E2 (Lemery, Mexico) }(42,43) \\
\text { MVA-E6-E7: Modified vaccine of Ankara encoding HPV-16 E6/E7 }\end{array}$ \\
\hline Synthetic viral vectors & $\begin{array}{l}\text { Risk of toxicity } \\
\text { Difficulty of production }\end{array}$ & $\begin{array}{l}\text { (Transgene, France) }(44,45) \\
\text { HPV-16 L1-E7 CVLP (Medigene, Germany) }(46,47) \\
\text { Lovaxin C: Attenuated Listeria monocytogenes vector encoding } \\
\text { HPV-16 E7 (Advaxis, NJ, USA) (49) }\end{array}$ \\
\hline Bacterial vectors & & $\begin{array}{l}\text { GLBL101c: Attenuated Lactobacillus casei vector encoding HPV-16 } \\
\text { E7 (Genolac BL Corp, Japan) (50) }\end{array}$ \\
\hline
\end{tabular}

CVLP, chimeric virus like particles; DNA, deoxyribonucleic acid; HPV, human papillomavirus; MHC, major histocompatibility complex; NCI, National Cancer Institute; PEK, PE-E7-KDEL3 fusion protein made with HPV-16 E7 peptide.

reason, the same investigators conducted a randomized trial in 51 patients with low-grade premalignant disorders (LSIL or persistent HPV infection) related to at least one HR-HPV (33\% HPV-16) with a two-year follow-up (23). The design was complex with a double subsequent randomization (vaccine vs. placebo) at inclusion and after one year. Adverse effects did not exceed grade 2 and were mainly flu-like symptoms (26\%). HPV-specific memory T-cell responses were detected at one year after vaccination and reactivity was maintained for at least 2 years. Among 37 patients vaccinated, the rates of cytological regression, persistence and progression were 51, 43 and $3 \%$ respectively at one year. The corresponding rates were 78,22 and $0 \%$ respectively in the placebo group $(n=9)$.
HPV-16 cleared in 3/8 vaccinated patients and in $1 / 2$ placebo patients. Thus, no significant difference was observed between both groups.

Protein-based vaccines. Protein-based vaccines pose no safety risk and are as easy to produce as peptide vaccines. In addition, they carry all possible antigen HLA epitopes and thus do not require the identification of patient HLA types. Protein-based vaccines tend to induce better antibody responses than cytotoxic $\mathrm{T}$ cell responses (16). They also suffer from low immunogenicity, which means that adjuvant and fusion protein strategies are required to improve vaccine effectiveness $(24,25)$. 
A fusion protein PD-E7 is made up of a mutated HPV-16 E7 associated with the first 108 amino acids of Haemophilus influenzae protein $\mathrm{D}$, formulated in the GlaxoSmithKline Biologicals adjuvant AS02B (26). In a phase I/II clinical trial, the vaccine was given to 9 patients ( 7 CIN3 and 2 CIN1, HPV-16 related), 3 intramuscular injections every 2 -weeks. Conization was performed 8 weeks after vaccination in patients with CIN3. Patients exhibited significant E7-specific cytotoxic T lymphocytes (CTL) responses. Following vaccination, no viral clearance or lesion regression was detected in CIN3 patients. This could be due to the fact that histological assessment took place early and the induction of only low-level immunization (27).

A phase I study tested a vaccine containing an HPV-16 E6/E7 fusion protein in association with the ISCOMATRIX adjuvant. The vaccine was administered subcutaneously 3 times every 3 weeks at escalating doses (20 to $200 \mu \mathrm{g}$ per dose) in 23 patients with CIN2/3. HPV16 was positive at inclusion in $65 \%$ of patients. A biopsy was carried out 2 weeks after the last injection. Immunization was shown to be safe and resulted in a humoral response with E6E7 specific IgG antibody and enhanced $\mathrm{CD}^{+} \mathrm{T}$ cell responses to both $\mathrm{E} 6$ and E7 antigens. All patients exhibited a reduction in HPV16 viral load on biopsy. No correlation between virological response and immunity was found. As the length of follow-up was very short, only 1 patient (4\%) had a histological response (no CIN) (28).

SGN-00101 vaccine (Stressgen, Nventa) is a fusion protein consisting of heat shock protein (Hsp) from Mycobacterium bovis and HPV 16 E7, administered subcutaneously (500 $\mu \mathrm{g}$ per dose) following two different protocols.

In the first study, 21 patients with CIN2/3 (18 CIN3), 24\% being positive for HPV16, received 4 injections 3 weeks apart and conization was performed at 15 weeks (29). Among the 20 patients assessed, the clinical and histological response was complete (no CIN or CIN1) in 8 patients (40\%). In eleven patients $(55 \%)$ the disease was stable and in one, the cancer progressed due to the extension of the lesion. No difference in response was found according to HPV type. A specific cell immune response assessed by ELISPOT was found in 9 of 17 patients (53\%). Among the 8 patients with complete response, 5 exhibited specific cell immunity suggesting a good correlation between efficacy and immunity. However, HPV clearance was associated with neither clinical nor immune response as only one of 19 patients $(5 \%)$ cleared HPV after follow-up.

In the second study, 58 patients with CIN3, 57\% being positive for HPV16, received 3 injections 4 weeks apart and conization was performed at 6 months (30). The clinical and histological response was complete (no CIN or CIN1) in 13 patients $(23 \%)$ and partial (reduction in lesion size by colposcopy $>50 \%$ ) in 32 patients $(55 \%)$. Eleven patients $(19 \%)$ had stable disease and 2 had microinvasive carcinoma. Serum IgG levels against HPV-16 E7 were found to have modestly increased after vaccination and tended to be correlated with a positive therapeutic effect (31). More complete responses, as well as significant higher HPV-16 E7 IgG levels, were observed in patients with recurring disease compared to patients who had never undergone conization. No difference in response was found according to HPV type.
In a third study (NCT00054041), patients with CIN3 received 3 subcutaneous injections of SGN-00101 4 weeks apart and had large loop excision of the transformation zone under colposcopy at week 15 . The study aimed to determine the efficacy of SGN-00101, with regard to complete histologic regression. The study was completed in January 2013, but no results were available in 2017.

TVGV-1 is composed of lyophilized PEK fusion protein (PE-E7-KDEL3 fusion protein made with HPV-16 E7 peptide) and GPI-0100. GPI-0100 is a semi-synthetic triterpene glycoside, originating in natural saponins, acting as an adjuvant for vaccines to improve the immunogenicity of proteins. A phase 2a double-blind, randomized, parallel group, dose-ranging study (NCT02576561) was conducted in 2015. The objective was to evaluate the safety and efficacy of three doses of TVGV-1 vaccine in comparison with its adjuvant, GPI-0100, in patients with histologically confirmed HPV-induced cervical CIN2/3. The outcome was the absence of CIN2/3 assessed by conization at 9 months. This study is currently recruiting participants.

\section{DNA-based vaccines}

DNA vaccines are safe, stable, and reasonably easy to produce. They do not elicit neutralizing antibody production, and any given patient can receive it over and over again. Genomic instability could theoretically be caused by DNA integrating the host genome, but no evidence of DNA integration in human tissues has been shown. DNA vaccines are made of E6 and/or E7 DNA and are not highly immunogenic since DNA is not naturally able to amplify or disperse from transfected cells to surrounding cells in vivo (16).

Among several DNA vaccines investigated in clinical trials, ZYC-101 appears to be the most advanced studied. ZYC-101 (ZYCOS, Inc., currently owned by MGI Pharma) is a microencapsulated DNA vaccine encoding multiple HLA-A2-restricted E7-derived epitopes. In a preliminary study including 15 women with CIN2/3, 5 had complete histological responses and 11 showed HPV specific T-cell responses (32). ZYC-101a, also called amolimogen, is the evolution of ZYC-101, encoding HPV-16 and HPV-18 E6and E7-derived epitopes. The vaccine was administered by intra-muscular route 3 times every 3 weeks at two doses (100 or $200 \mu \mathrm{g}$ ) in a randomized trial to compare the efficacy of the vaccine $(n=86)$ vs. placebo $(n=41)(33)$.

All patients had CIN2/3 and 56\% were positive for HPV-16 or HPV-18. A conization was performed at 6 months. A histological response (no CIN or CIN1) was observed in 37 vaccinated patients $(43 \%)$ and 11 controls $(27 \%)$. In the subgroup of patients aged under $25(n=43)$, the histological response was significantly higher $(70 \%)$ after immunotherapy than in the control group (23\%). Neither the dose of vaccine nor the HPV genotype influenced results. The vaccine was well tolerated. No virological or immune data were available for this study.

This vaccine reached phase 3 and a multicenter, double-blind, randomized, placebo-controlled study was carried out in 2005 (NCT00264732). Inclusion criteria were women between the ages of 13 and 25 with a CIN 2/3 identified by a colposcopically directed punch biopsy and a colposcopi- 
cally visible lesion that does not involve more than $75 \%$ of the cervix. The efficacy of ZYC 101a was assessed by colposcopy and biopsy, 6 months after the vaccination. However, no results were available in 2017, suggesting abandonment of the publication process.

VGX-3100, a DNA vaccine containing plasmids targeting HPV 16 and 18 E6 and E7 proteins was used in clinical trials employing electroporation technology which consists in administering the vaccine through an intramuscular injection then electroporation with several devices delivering a small electrical charge. In a phase 1 clinical trial, $T$ cell and antibody responses were observed in $78 \%$ of patients vaccinated using VGX-3100 (34).

In a phase 2 multicenter clinical trial, 167 patients with CIN2/3 were randomized (3:1) to receive $6 \mathrm{mg}$ VGX-3100 or placebo at 0,4 , and 12 weeks. Regression to CIN1 or normal pathology 36 weeks after the first dose constituted the primary efficacy endpoint. Fifty-three (49.5\%) of 107 VGX-3100 recipients and $11(30.6 \%)$ of 36 placebo recipients were found to have histopathological regression $(\mathrm{P}=0.034)$ in the per-protocol analysis. Similar significant difference was observed in the modified intention-to-treat analysis. Reactions at the injection site were observed in the majority of women, however in the VGX-3100 group erythema was the sole significantly more frequent side-effect $(78.4 \%)$ compared to the placebo group (57.1\%), ( $\mathrm{P}=0.007)(35)$.

In a pilot study, patients with HPV-16 CIN2/3 received a DNA vaccine pnGVL4a-CRT/E7 (Detox) via different administration routes: Intradermally, intramuscularly, or intralesionally (36). Thirty-two patients were enrolled and toxicity and immunogenicity were evaluated at 2 years. In 8 out of 27 (30\%) women who were given all vaccinations and underwent conization, histologic regression to CIN 1 or less was observed. Twenty-two out of 32 patients (69\%) experienced adverse events (grade 1 or less in severity) specifically related to the vaccine. In subject-matched comparisons, there was an increase in intraepithelial $\mathrm{CD}^{+} \mathrm{T}$ cell infiltrates following vaccination in patients belonging to the intralesional administration cohort.

Sig/E7 (Detox)/Hsp70 is a DNA vaccine encoding an endoplasmic reticulum signal sequence (Sig), associated with an attenuated form of HPV 16 E7 fused to Hsp70. The vaccine was administered by intramuscular route 3 times, 4 weeks apart at escalating doses ( 0.5 to $3 \mathrm{mg}$ per dose) in 15 patients with CIN2/3 all HPV16 positive (37). A conization was performed at 15 weeks. A histological response (no CIN) was observed in $0 / 6$ patients at low dose and in 3/9 patients (33\%) at high dose. E6E7 specific IgG antibodies were found in 13 to $20 \%$ of patients at entry, but were not boosted after vaccination. Cell mediated immunity was variable after vaccination. No correlation with histological response was observed. Adjuvating treatments like TLR7 agonist, imiquimod, were tested in association with the vaccine to increase its immunogenicity. The efficacy and safety of Sig/E7 (Detox)/Hsp70 administered with topical imiquimod were assessed in a phase 1 clinical trial (NCT00788164). Results were not available in 2017.

A Korean open-label, dose-escalation, single-center, phase 1 study examined how safe GX-188E, a DNA-based therapeutic vaccine, administered via electroporation in subjects with
HPV-16 or HPV-18-associated CIN3 (NCT01634503) was. Each patient was given an intramuscular 1,2 or $4 \mathrm{mg}$ injection of GX-188E by electroporation 3 times every 4 weeks. The results were assessed 24 weeks after the third injection. The study was completed in 2014, but no results were available in 2017. A multi-center randomized, double-blind, placebo-controlled, phase 2 clinical trial evaluated the safety and efficacy of GX-188E at a dose of $1 \mathrm{mg}$ by electroporation 3 times every 4 weeks (NCT02596243). The outcome measures were the rate of histopathological regression of cervical lesions to CIN1 or less and the clearance of HPV 16 or 18 at 36 weeks. This study is scheduled to end in 2018.

A phase 1-2 prospective multi-center study in Germany evaluated the safety, the immunogenicity, and the efficacy of VB10 in 16 patients with HPV16 related CIN2/3 lesions (NCT02529930). The vaccine was administered intramuscularly every 3 weeks 3 times apart. This study is still recruiting participants in 2017.

\section{Live-vector-based vaccines}

Live-vector-based vaccines classically include viral vectors (adenovirus, vaccinia virus) and bacterial vectors (listeria, lactobacillus). Like protein-based vaccines, these vaccines deliver the antigen to dendritic cells, thus expressing HPV E6 and/or E7 in order to treat HPV-associated malignancies. Live-vector-based vaccines exhibit strong immunogenicity due to their ability to replicate inside host cells and facilitate the spread of antigen inside cells. However, the production of neutralizing antibodies in the host during vaccination could diminish the efficacy of repeat immunizations. Using live vectors may also be associated with a risk of toxicity (16).

Natural viral vectors. Among viral vectors, the vaccinia virus is the most highly developed because of its high efficiency of antigen-specific immunotherapy. The other vectors tested, such as the Semliki Forest virus encoding E7, have been shown to induce strong immune responses in mice, but failed to demonstrate any clinical responses, possibly because of the immune tolerance of HPV-infected cells $(38,39)$.

TA-HPV, a recombinant vaccinia vector encoding an HPV-16/18 E6/E7 fusion protein was assessed in Phase 1/2 clinical trials. It was well tolerated and induced T-cell-mediated immune responses in women with cervical cancer although no trials have been set up for women with CIN $(40,41)$.

The modified vaccine of Ankara (MVA) has been developed as a recombinant vaccinia vector carrying nucleotidic sequences encoding either bovine papillomavirus E2 protein (MVA-E2), or HPV-16 E6 and E7 proteins (MVA-E6-E7).

After cervical injection of MVA E2 (Lemery, Mexico), patients produced antibodies against the MVA-E2 vaccine and developed a specific cytotoxic T lymphocyte (CTL) response against HPV-transformed cells (42).

The originality of the MVA E2 recombinant vaccinia virus is that it activates the immune system against $\mathrm{E} 2$ antigen, which has an important part to play by increasing the expression of E6 and E7. However, these studies did not demonstrate that MVA E2 induced an E2-specific immune response. Moreover, the agent does not focus exclusively on HPV16, as containing bovine papillomavirus. The vaccine was administered by the 


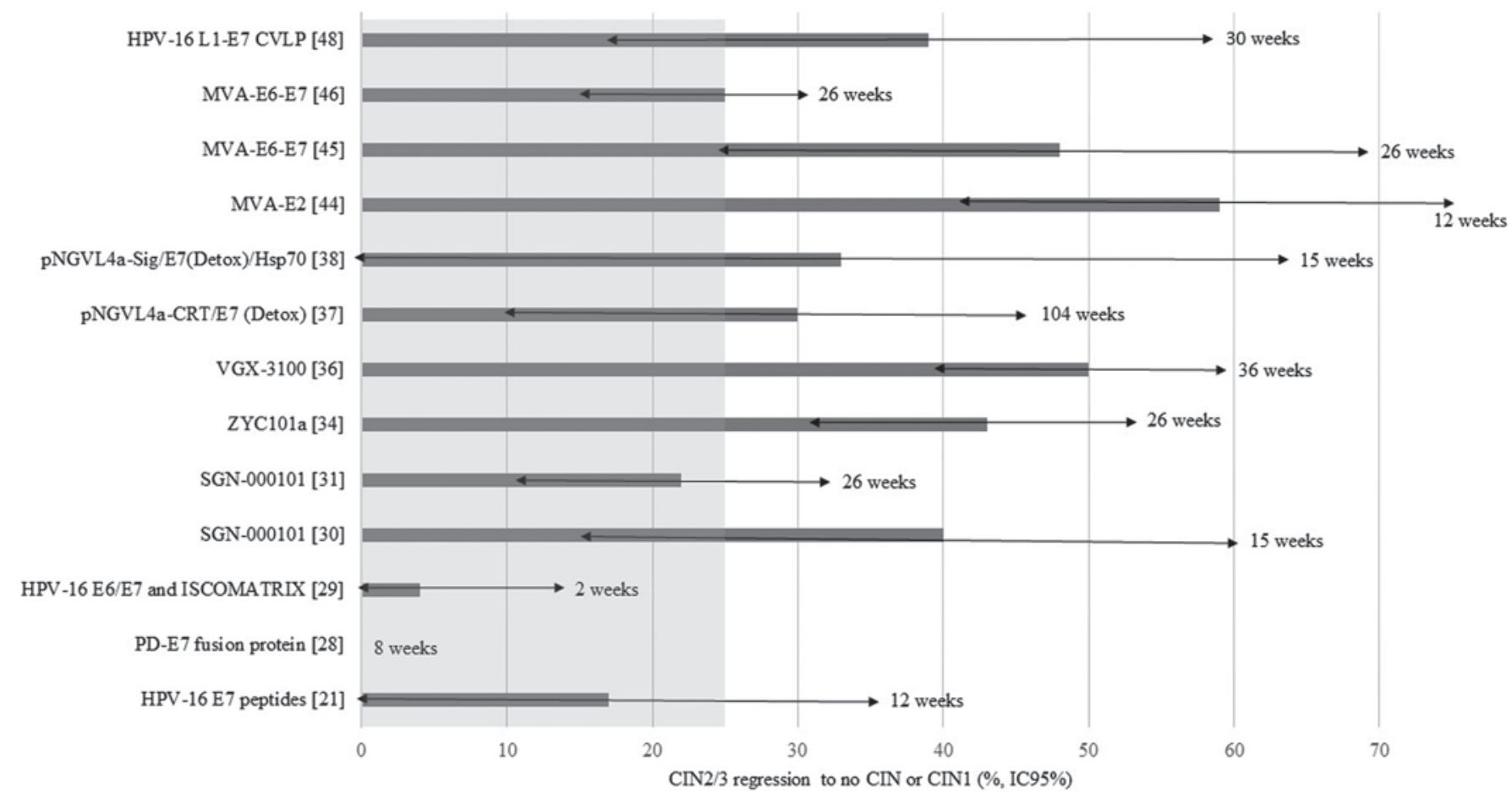

Estimated rate of spontaneous regression of $\mathrm{CIN} 2 / 3$ at 6 months managed expectantly

Figure 1. Regression of CIN2/3 to no CIN or CIN1 after targeted immunotherapy. Among all formulations, the DNA vaccines ZYC-101a and VGX-3100, as well as the viral-vector-based vaccine MVA E2, demonstrated a higher rate of CIN2/3 reduction than the spontaneous resolution rate expected at 6 months.

intra-cervical route 6 times, 1 week a part. Thirty-four patients with CIN3, all related to HPV 16 or 18 , were treated and assessed by conization at 12 weeks (43). The clinical response was complete (no more lesion) in 19 patients (56\%) and partial (reduction in lesion size by colposcopy $>50 \%$ ) in 11 patients (32\%). A histological response (no CIN or CIN1) was obtained in 20 patients $(59 \%)$. All patients had a humoral and cell mediated immunity as shown by MVA E2 IgG antibodies and specific cytotoxic T lymphocytes. HPV cleared in 12 patients (35\%) and the viral load was reduced by $95 \%$ in 5 patients (15\%). Histology was well correlated with virology, as 15 of 20 CIN1-had a viral load reduced by 95 to $100 \%$.

MVA-E6-E7 (Transgene, France) is administered subcutaneously 3 times, 1 week apart. In a phase 2 study including 21 patients with CIN2/3, all positive for HPV-16, the efficacy of vaccination was assessed by colposcopy, cytology, and virology at 6 months (44). Conization was performed if any anomalies or discordances were found. Follow-up extended to 12 months. A complete clinical and/or histological response (no CIN or CIN1) was observed in 10 patients (48\%). HPV16 cleared on smears in 9 patients (43\%). Histology was well correlated with virology, as 7 of 10 patients with no CIN or CIN1 cleared HPV16 mRNA. No recurrence of CIN2/3 was seen at 1 year. Following treatment with TG4001, no patient developed or enhanced an IgG antibody response to E6 or E7. Cell immune data was not available in this study.

Amulti-centerrandomized,double-blind,placebo-controlled, phase $2 \mathrm{~b}$ clinical trial was conducted to assess the efficacy and the safety of MVA-E6-E7 in 206 patients with HPV-related CIN 2/3 (45). The vaccine's safety profile is just as good as in former trials. Histological resolution (no CIN) at 6 months was significantly higher in vaccinated patients $11 / 55(20 \%)$ than in controls 1/27 (4\%) $(\mathrm{P}=0.049)$ in HPV-16 mono-infected patients, as well as in patients infected by all HPV genotypes, 32/129 (25\%) vs. 6/63 (10\%) respectively ( $\mathrm{P}=0.013)$. The viral clearance was significantly higher in vaccinated patients $20 / 52(38 \%)$ than controls $2 / 23(9 \%)(\mathrm{P}=0.009)$ in HPV-16 mono-infected patients, as well as in patients infected by all HPV genotypes, 45/121 (37\%) vs. $8 / 58$ patients $(14 \%),(\mathrm{P}=0.001)$. However, the trial did not meet its primary endpoint of $60 \%$ resolution at six-months of CIN 2/3 in the HPV-16 mono-infected population. Therefore, Transgene did not further develop TG4001 for this indication.

Synthetic viral vectors. Chimeric virus-like particles (CVLP) can be produced using the same technology as for HPV prophylactic vaccines since they are easy to manufacture, able to compact DNA, and target specific cell receptors. HPV-16 L1-E7 CVLP consists of a carboxy-terminally truncated HPV16 L1 protein fused to the amino-terminal part of the HPV-16 E7 protein and self-assembled by recombinant expression of the fusion protein (MediGene). HPV16 L1-E7 CVLP has been shown to induce E7-specific cellular immunity in mice (46). A randomized, double-blind, placebo-controlled clinical trial has been conducted in HPV-16 related CIN 2/3 patients. CVLP was administered subcutaneously 4 times over 12 weeks at two doses (75 or $250 \mu \mathrm{g}$ ) in 23 patients with CIN2/3, while 12 patients received placebo (47). All were assessed by colposcopy and biopsy at 7 months. A histological response (no CIN or CIN1) was observed in 9 vaccinated patients (39\%) and 3 controls (25\%). HPV16 cleared on biopsy in 6/16 vaccinated patients (37\%) and 1/7 controls (14\%). Histology was well correlated with virology, as $85 \%$ of patients responding 
to immunotherapy (no CIN or CIN1) cleared HPV16 DNA HPV16 E7 antibodies negative at baseline were positive in 10 vaccinated patients (42\%). An E7 specific T cell response was observed in $22 \%$ of vaccinated patients, but was not correlated with histological response. Antibodies with high titers against HPV 16 L1 and low titers against HPV 16 E7 were induced.

Bacterial vectors. Listeria-based vaccines have been shown to be able to produce $\mathrm{CD}^{+}$and $\mathrm{CD} 4^{+}$immune responses as well as inducing tumor-regression in animal models (48). Lm-LLO-E7, also called ADXS11-001 or Lovaxin C (Advaxis, Princeton, NJ, USA) consists in a live attenuated Listeria monocytogenes vector secreting HPV-16 E7 fused to listerioly-sin 0 . This vaccine was safe in phase 1 trials and induced immunological responses in patients with advanced cervical cancer (49). An American randomized, single-blind, placebo controlled phase 2 study was conducted to evaluate the safety and efficacy of Lovaxin C for CIN2/3 therapy. The vaccine was administered intravenously at escalating doses twice, 4 weeks a part (NCT01116245). No results are available as the study was stopped prematurely due to lack of enrollment.

An attenuated Lactobacillus casei expressing modified full-length HPV16 E7 protein was evaluated in 10 patients with HPV16-associated CIN3. The vaccine was administered orally. After 9 weeks of therapy, the lesion downgraded to CIN2 in $70 \%$ of patients. E7 cell-mediated immune responses in cervical lymphocytes were directly correlated to the pathological downgrade. E7-specific mucosal immunity in cervical lesions in the uterus were elicited by the vaccine (50).

\section{Conclusion}

The present review has identified eighteen vaccines for treating CIN at various stages of development, and primarily described phase 2/3 studies. Most of them were well tolerated. Adverse reactions were principally injection site reactions and flu-like symptoms less than grade 2 .

Most of the vaccines investigated were demonstrated to bring about E6 or E7 specific T cell response, but did not show a correlation linking histological or virological response and immune $\mathrm{T}$ cell responses.

The efficacy of vaccines defined by regression of CIN2/3 to no CIN or CIN1 ranged from 17 to $59 \%$ after a minimum of a twelve-week follow-up (Fig. 1). An additional value is occurred by some of the vaccines, as the expected spontaneous regression rate of $\mathrm{CIN} 2 / 3$ provided by randomized studies (placebo arm) is $10-30 \%(33,35,45)$.

However, the definitions of inclusion criteria (both CIN2 and CIN3) and of pathological response (no CIN or CIN1) commonly used in clinical reports remain debatable. The diagnosis of CIN2 is subjective in that it depends on the colposcopy which guides the biopsy and on the variability of the pathological examination. Although CIN2 and CIN3 are included in the same high grade lesion group, CIN2 is known to be a heterogeneous entity including both real CIN3 and also condylomatous lesion or CIN1 (51). It is for this reason that the reproducibility of the diagnosis is low for CIN2. To avoid any possible confusion, some published studies and on-going clinical trials include only true CIN3 $(29,30,50)$; others considering that no CIN was the only response criterion $(20,28,37,45)$.
Colposcopy also has inherent limitations and may lead to the misdiagnose some CIN2/3. The sensitivity of colposcopy is classically over $65 \%$, and may exceed $80 \%$ in countries where cervical cancer programs are available (52). However, specificity is lower as colposcopy also detects more clinically insignificant low grade lesions (53).

Some clinical trials have assessed viral regression and clinical response after immunotherapy, but the results are controversial. Only 3 studies showed a correlation between histological and virological response $(43,44,47)$. Two studies demonstrated a high proportion of HPV clearance, while the pathological response rate was low $(20,28)$. One study failed to demonstrate viral clearance when lesions were cured (29).

None of the clinical trials reported in this paper suggest the production and marketing of targeted immunotherapy against CIN2/3 in the near future. However, as long as immunotherapies can demonstrate efficacy over observation with no major side effects, research and development of this concept should be encouraged. Indeed, HPV related diseases are dramatically increasing, especially in young women where current US guidelines no longer recommend surgical conization for women aged 21-24 with CIN2 (54). In addition, prophylactic vaccines are not covering the population worldwide, either because the license is not available or the coverage remains low, as in France where vaccination is individual and not organized (55). Alternatives to conization are necessary in order to preserve reproductive outcome, avoid HPV persistence and facilitate colposcopic surveillance. Unfortunately some vaccines are no longer being investigated for this indication, whereas other have regressed to phase $1 / 2$ due to the addition of new adjuvants to increase immunogenicity and hopefully efficacy.

\section{References}

1. Kyrgiou M, Athanasiou A, Paraskevaidi M, Mitra A, Kalliala I, Martin-Hirsch P, Arbyn M, Bennett P and Paraskevaidis E: Adverse obstetric outcomes after local treatment for cervical preinvasive and early invasive disease according to cone depth: Systematic review and meta-analysis. BMJ 354: i3633, 2016.

2. Arbyn M, Kyrgiou M, Simoens C, Raifu AO, Koliopoulos G, Martin-Hirsch P, Prendiville W and Paraskevaidis E: Perinatal mortality and other severe adverse pregnancy outcomes associated with treatment of cervical intraepithelial neoplasia: Meta-analysis. BMJ 337: a1284, 2008.

3. Albrechtsen S, Rasmussen S, Thoresen S, Irgens LM and Iversen OE: Pregnancy outcome in women before and after cervical conisation: Population based cohort study. BMJ 337: a1343, 2008.

4. Kreimer AR, Guido RS, Solomon D, Schiffman M, Wacholder S, Jeronimo J, Wheeler CM and Castle PE: Human papillomavirus testing following loop electrosurgical excision procedure identifies women at risk for posttreatment cervical intraepithelial neoplasia grade 2 or 3 disease. Cancer Epidemiol Biomarkers Prev 15: 908-914, 2006.

5. Hildesheim A, Herrero R, Wacholder S, Rodriguez AC, Solomon D, Bratti MC, Schiller JT, Gonzalez P, Dubin G, Porras C, et al: Costa rican HPV vaccine trial group: effect of human papillomavirus 16/18 11 viruslike particle vaccine among young women with preexisting infection: A randomized trial. JAMA 298: 743-753, 2007.

6. FUTURE IIStudy Group: Quadrivalent vaccine against human papillomavirus to prevent high-grade cervical lesions. N Engl J Med 356: 1915-1927, 2007.

7. Young JL, Jazaeri AA, Darus CJ and Modesitt SC: Cyclooxygenase-2 in cervical neoplasia: A review. Gynecol Oncol 109: 140-145, 2008.

8. Kim HS, Kim T, Kim MK, Suh DH, Chung HH and Song YS: Cyclooxygenase-1 and -2: Molecular targets for cervical neoplasia. J Cancer Prev 18: 123-134, 2013. 
9. Grabosch SM, Shariff OM, Wulff JL and Helm CW: Non-steroidal anti-inflammatory agents to induce regression and prevent the progression of cervical intraepithelial neoplasia. Cochrane Database Syst Rev 9: CD004121, 2014.

10. zur Hausen H: Papillomaviruses and cancer: From basic studies to clinical application. Nat Rev Cancer 2: 342-350, 2002.

11. Badaracco G and Venuti A: Human papillomavirus therapeutic vaccines in head and neck tumors. Expert Rev Anticancer Ther 7: 753-766, 2007.

12. Li N, Franceschi S, Howell-Jones R, Snijders PJ and Clifford GM: Human papillomavirus type distribution in 30,848 invasive cervical cancers worldwide: Variation by geographical region, histological type and year of publication. Int J Cancer 128 : 927-935, 2011

13. Tjalma WA, Fiander A, Reich O, Powell N, Nowakowski AM, Kirschner B, Koiss R, O'Leary J, Joura EA, Rosenlund M, et al: Differences in human papillomavirus type distribution in high-grade cervical intraepithelial neoplasia and invasive cervical cancer in Europe. Int J Cancer 132: 854-867, 2013.

14. van Poelgeest MI, Welters MJ, van Esch EM, Stynenbosch LF, Kerpershoek G, van Persijn van Meerten EL, van den Hende M, Löwik MJ, Berends-van der Meer DM, Fathers LM, et al: HPV16 synthetic long peptide (HPV16-SLP) vaccination therapy of patients with advanced or recurrent HPV16-induced gynecological carcinoma, a phase II trial. J Transl Med 11: 88, 2013

15. Su JH, Wu A, Scotney E, Ma B, Monie A, Hung CF and Wu TC: Immunotherapy for cervical cancer: Research status and clinical potential. BioDrugs 24: 109-129, 2010.

16. Hung CF, Ma B, Monie A, Tsen SW and Wu TC: Therapeutic human papillomavirus vaccines: Current clinical trials and future directions. Expert Opin Biol Ther 8: 421-439, 2008.

17. Ressing ME, van Driel WJ, Brandt RM, Kenter GG, de Jong JH, Bauknecht T, Fleuren GJ, Hoogerhout P, Offringa R, Sette A, et al: Detection of T helper responses, but not of human papillomavirus-specific cytotoxic $\mathrm{T}$ lymphocyte responses, after peptide vaccination of patients with cervical carcinoma. J Immunother 23: 255-266, 2000.

18. van Driel WJ, Ressing ME, Kenter GG, Brandt RM, Krul EJ, van Rossum AB, Schuuring E, Offringa R, Bauknecht $T$, Tamm-Hermelink A, et al: Vaccination with HPV16 peptides of patients with advanced cervical carcinoma: Clinical evaluation of a phase I-II trial. Eur J Cancer 35: 946-952, 1999.

19. Welters MJ, Kenter GG, Piersma SJ, Vloon AP, Löwik MJ, Berends-van der Meer DM, Drijfhout JW, Valentijn AR, Wafelman AR, Oostendorp J, et al: Induction of tumor-specific CD4+ and CD8+ T-cell immunity in cervical cancer patients by a human papillomavirus type 16 E6 and E7 long peptides vaccine. Clin Cancer Res 14: 178-187, 2008.

20. Muderspach L, Wilczynski S, Roman L, Bade L, Felix J, Small LA Kast WM, Fascio G, Marty V and Weber J: A phase I trial of a human papillomavirus (HPV) peptide vaccine for women with high-grade cervical and vulvar intraepithelial neoplasia who are HPV 16 positive. Clin Cancer Res 6: 3406-3416, 2000.

21. Kenter GG, Welters MJ, Valentijn AR, Lowik MJ, Berends-van der Meer DM, Vloon AP, Essahsah F, Fathers LM, Offringa R, Driifhout JW, et al: Vaccination against HPV-16 oncoproteins for vulvar intraepithelial neoplasia. N Engl J Med 361: 1838-1847, 2009.

22. de Vos van Steenwijk PJ, Ramwadhdoebe TH, Löwik MJ, van der Minne CE, Berends-van der Meer DM, Fathers LM, Valentijn AR, Oostendorp J, Fleuren GJ, Hellebrekers BW, et al: A placebo-controlled randomized HPV16 synthetic long-peptide vaccination study in women with high-grade cervical squamous intraepithelial lesions. Cancer Immunol Immunother 61: $1485-1492,2012$

23. de Vos van Steenwijk PJ, van Poelgeest MI, Ramwadhdoebe TH, Löwik MJ, Berends-van der Meer DM, van der Minne CE, Loof NM, Stynenbosch LF, Fathers LM, Valentijn AR, et al: The long-term immune response after HPV16 peptide vaccination in women with low-grade pre-malignant disorders of the uterine cervix: A placebo-controlled phase II study. Cancer Immunol Immunother 63: 147-160, 2014

24. Cui Z and Huang L: Liposome-polycation-DNA (LPD) particle as a carrier and adjuvant for protein-based vaccines: Therapeutic effect against cervical cancer. Cancer Immunol Immunother 54: 1180-1190, 2005

25. Stewart TJ, Drane D, Malliaros J, Elmer H, Malcolm KM, Cox JC, Edwards SJ, Frazer IH and Fernando GJ: ISCOMATRIX adjuvant: An adjuvant suitable for use in anticancer vaccines. Vaccine 22: 3738-3743, 2004.
26. Hallez S, Simon P, Maudoux F, Doyen J, Noël JC, Beliard A Capelle X, Buxant F, Fayt I, Lagrost AC, et al: Phase I/II trial of immunogenicity of a human papillomavirus (HPV) type 16 E7 protein-based vaccine in women with oncogenic HPV-positive cervical intraepithelial neoplasia. Cancer Immuno Immunother 53: 642-650, 2004.

27. Simon P, Buxant F, Hallez S, Burny A, Fayt I, Anaf V and Noël JC: Cervical response to vaccination against HPV16 E7 in case of severe dysplasia. Eur J Obstet Gynecol Reprod Biol 109: 219-223, 2003

28. Frazer IH, Quinn M, Nicklin JL, Tan J, Perrin LC, Ng P, O'Connor VM, White O, Wendt $\mathrm{N}$ and Martin J: Phase 1 study of HPV16-specific immunotherapy with E6E7 fusion protein and ISCOMATRIX adjuvant in women with cervical intraepithelial neoplasia. Vaccine 23: 172-181, 2004.

29. Roman LD, Wilczynski S, Muderspach LI, Burnett AF, O'Meara A, Brinkman JA, Kast WM, Facio G, Felix JC, Aldana M and Weber JS: A phase II study of Hsp-7 (SGN-00101) in women with high-grade cervical intraepithelial neoplasia. Gynecol Oncol 106: 558-566, 2007.

30. Einstein MH, Kadish AS, Burk RD, Kim MY, Wadler S, Streicher H, Goldberg GL and Runowicz CD: Heat shock fusion protein-based immunotherapy for treatment of cervical intraepithelial neoplasia III. Gynecol Oncol 106: 453-460, 2007.

31. Van Doorslaer K, Reimers LL, Studentsov YY, Einstein MH and Burk RD: Serological response to an HPV16 E7 based therapeutic vaccine in women with high-grade cervical dysplasia. Gynecol Oncol 116: 208-212,2010.

32. Sheets EE, Urban RG, Crum CP, Hedley ML, Politch JA, Gold MA, Muderspach LI, Cole GA and Crowley-Nowick PA: Immunotherapy of human cervical high-grade cervical intraepithelial neoplasia with microparticle-delivered human papillomavirus 16 E7 plasmid DNA. Am J Obstet Gynecol 188 916-926, 2003

33. Garcia F, Petry KU, Muderspach L, Gold MA, Braly P, Crum CP Magill M, Silverman M, Urban RG, Hedley ML and Beach KJ: ZYC101a for treatment of high-grade cervical intraepithelial neoplasia: A randomized controlled trial. Obstet Gynecol 103 : 317-326, 2004

34. Bagarazzi ML, Yan J, Morrow MP, Shen X, Parker RL, Lee JC, Giffear M, Pankhong P, Khan AS, Broderick KE, et al: Immunotherapy against HPV16/18 generates potent TH1 and cytotoxic cellular immune responses. Sci Transl Med 4 $155 \mathrm{ra138}, 2012$

35. Trimble CL, Morrow MP, Kraynyak KA, Shen X, Dallas M, Yan J, Edwards L, Parker RL, Denny L, Giffear M, et al: Safety, efficacy and immunogenicity of VGX-3100, a therapeutic synthetic DNA vaccine targeting human papillomavirus 16 and 18 E6 and E7 proteins for cervical intraepithelial neoplasia 2/3: A randomised, double-blind, placebo-controlled phase $2 \mathrm{~b}$ trial. Lancet 386: 2078-2088, 2015

36. Alvarez RD, Huh WK, Bae S, Lamb LS Jr, Conner MG, Boyer J, Wang C, Hung CF, Sauter E, Paradis M, et al: A pilot study of pNGVL4a-CRT/E7 (detox) for the treatment of patients with HPV16+ cervical intraepithelial neoplasia 2/3 (CIN2/3). Gynecol Oncol 140: 245-252, 2016.

37. Trimble CL, Peng S, Kos F, Gravitt P, Viscidi R, Sugar E, Pardoll D and Wu TC: A phase I trial of a human papillomavirus DNA vaccine for HPV16+ cervical intraepithelial neoplasia 2/3. Clin Cancer Res 15: 361-367, 2009.

38. Riezebos-Brilman A, Regts J, Freyschmidt EJ, Dontje B, Wilschut $J$ and Daemen T: Induction of human papilloma virus E6/E7-specific cytotoxic T-lymphocyte activity in immune-tolerant, E6/E7-transgenic mice. Gene Ther 12: $1410-1414,2005$

39. Hsieh CJ, Kim TW, Hung CF, Juang J, Moniz M, Boyd DA, He L, Chen PJ, Chen CH and Wu TC: Enhancement of vaccinia vaccine potency by linkage of tumor antigen gene to gene encoding calreticulin. Vaccine 22: 3993-4001, 2004.

40. Borysiewicz LK, Fiander A, Nimako M, Man S, Wilkinson GW, Westmoreland D, Evans AS, Adams M, Stacey SN, Boursnell ME, et al: A recombinant vaccinia virus encoding human papillomavirus types 16 and 18, E6 and E7 proteins as immunotherapy for cervical cancer. Lancet 347: 1523-1527, 1996.

41. Kaufmann AM, Stern PL, Rankin EM, Sommer H, Nuessler V, Schneider A, Adams M, Onon TS, Bauknecht T, Wagner U, et al: Safety and immunogenicity of TA-HPV, a recombinant vaccinia virus expressing modified human papillomavirus (HPV)-16 and HPV-18 E6 and E7 genes, in women with progressive cervical cancer. Clin Cancer Res 8: 3676-3685, 2002 
42. Corona Gutierrez CM, Tinoco A, Navarro T, Contreras ML, Cortes RR, Calzado P, Reyes L, Posternak R, Morosoli G, Verde ML and Rosales R: Therapeutic vaccination with MVA E2 can eliminate precancerous lesions (CIN 1, CIN 2 and CIN 3) associated with infection by oncogenic human papillomavirus. Hum Gene Ther 15: 421-431, 2004.

43. García-Hernández E, González-Sánchez JL, Andrade-Manzano A, Contreras ML, Padilla S, Guzmán CC, Jiménez R, Reyes L, Morosoli G, Verde ML and Rosales R: Regression of papilloma high-grade lesions (CIN 2 and CIN 3 ) is stimulated by therapeutic vaccination with MVA E2 recombinant vaccine. Cancer Gene Ther 13: 592-597, 2006.

44. Brun JL, Dalstein V, Leveque J, Mathevet P, Raulic P, Baldauf JJ, Scholl S, Huynh B, Douvier S, Riethmuller D, et al: Regression of high-grade cervical intraepithelial neoplasia with TG4001 targeted immunotherapy. Am J Obstet Gynecol 204: 169.e1-e8, 2011.

45. Transgene: Transgene reports randomized phase $2 \mathrm{~b}$ data with its therapeutic HPV vaccine TG4001 in women with CIN2/3 intraepithelial cervical neoplasia. https://www.transgene.fr/wp-content/ uploads/PR/208_en.pdf. Accessed November 11, 2017.

46. Sharma C, Dey B, Wahiduzzaman M and Singh N: Human papillomavirus 16 L1-E7 chimeric virus like particles show prophylactic and therapeutic efficacy in murine model of cervical cancer. Vaccine 30: 5417-5424, 2012.

47. Kaufmann AM, Nieland JD, Jochmus I, Baur S, Friese K, Gabelsberger J, Gieseking F, Gissmann L, Glasschröder B, Grubert T, et al: Vaccination trial with HPV16 L1E7 chimeric virus-like particles in women suffering from high grade cervical intraepithelial neoplasia (CIN 2/3). Int J Cancer 121: 2794-2800, 2007.

48. Souders NC, Sewell DA, Pan ZK, Hussain SF, Rodriguez A, Wallecha A and Paterson Y: Listeria-based vaccines can overcome tolerance by expanding low avidity $\mathrm{CD} 8+\mathrm{T}$ cells capable of eradicating a solid tumor in a transgenic mouse model of cancer. Cancer Immun 7 $2,2007$.
49. Maciag PC, Radulovic S and Rothman J: The first clinical use of a live-attenuated Listeria monocytogenes vaccine: A Phase I safety study of Lm-LLO-E7 in patients with advanced carcinoma of the cervix. Vaccine 27: 3975-3983, 2009.

50. Kawana K,Adachi K,KojimaS,Taguchi A,Tomio K, Yamashita A, Nishida H, Nagasaka K, Arimoto T, Yokoyama T, et al: Oral vaccination against HPV E7 for treatment of cervical intraepithelial neoplasia grade 3 (CIN3) elicits E7-specific mucosal immunity in the cervix of CIN3 patients. Vaccine 32: 6233-6239, 2014.

51. Stoler M, Bergeron C, Colgan T, Ferenczy A, Herrington C, Kim K, Loening T, Schneider A, Sherman M, Wilbur D, et al: Squamous cell tumours and precursors. WHO Classification of tumours of the uterine cervix. IARC Press, pp172-181, 2014.

52. Decker KM, McLachlin CM and Lotocki R; Pan-canadian cervical cancer screening network monitoring program performance working group: Performance measures related to colposcopy for canadian cervical cancer screening programs: Identifying areas for improvement. J Obstet Gynaecol Can 37: 245-251, 2015

53. Kyrgiou M, Kalliala IE, Mitra A, Fotopoulou C, Ghaem-Maghami S, Martin-Hirsch PP, Cruickshank M, Arbyn $\mathrm{M}$ and Paraskevaidis E: Immediate referral to colposcopy versus cytological surveillance for minor cervical cytological abnormalities in the absence of HPV test. Cochrane Database Syst Rev 1: CD009836, 2017.

54. Partridge EE, Abu-Rustum N, Giuliano A, Massad S, McClure J, Dwyer $M$ and Hughes $M$; National comprehensive cancer network: Cervical cancer screening. J Natl Compr Canc Netw 12: 333-341, 2014.

55. Denis F, Cohen R, Stahl JP, Martinot A, Dury V, Le Danvic M and Gaudelus J: Papillomavirus vaccination in France according to 2008 to 2012 Vaccinoscopie $^{(\mathbb{})}$ data. Med Mal Infect 44: 18-24, 2014. 